\title{
Aplicativo ERA: uma estratégia para aprendizagem de vocabulário de línguas adicionais com o uso de Realidade
}

\section{Aumentada}

Emanuele Krewer $^{\star}$, Angelise Fagundes da Silva ${ }^{\star *}$, Marcus Vinícius Liessem Fontana ${ }^{* * *}$

\section{Resumo}

Este trabalho objetiva apresentar e refletir sobre algumas estratégias utilizadas para a aprendizagem de vocabulário de línguas adicionais, especialmente no que diz respeito às atividades que envolvem os recursos visuais e o uso de tecnologia de Realidade Aumentada (RA). Sendo assim, buscamos investigar as estratégias mais relevantes e usuais e como os recursos visuais e as tecnologias de RA podem contribuir em tal processo. Além disso, apresentaremos um aplicativo de RA que desenvolvemos para tradução de palavras em espanhol. Esse aplicativo foi nomeado de ERA, Espanhol Realidade Aumentada.

Palavras-chave: Espanhol, estratégias, aprendizagem, vocabulário, Realidade Aumentada.

\section{Introdução}

Refletir sobre o ensino e a aprendizagem de línguas adicionais requer que consideremos vários aspectos. Esses vão desde questões estruturais, relacionados à gramática até questões culturais de uma determinada língua e do povo que a fala. Entre todos esses aspectos vale ressaltar o vocabulário.

Acadêmica do curso de Letras- Português e Espanhol na Universidade Federal da Fronteira Sul, Campus Cerro Largo - emanuelekrewericr@gmail.com

* Doutora em Educação pelo Programa de Pós-Graduação em Educação da Universidade Federal de Santa Maria - angelisef@gmail.com

*** Doutor em Educação pelo Programa de Pós-Graduação em Educação da Universidade Federal de Santa Maria - marcusfontana2011@gmail.com 
Aprender e enriquecer o vocabulário da língua adicional é algo que determina o desempenho comunicativo do aprendiz, assim como apresenta Leffa (2016, p. 19): "Língua não é só léxico, mas o léxico é o elemento que melhor a caracteriza e a distingue das outras".

Neste sentido, é importante frisar que utilizaremos o termo "língua adicional" ao invés de "língua estrangeira", uma vez que o falante já possui uma língua, que é a sua materna, e essa nova vem como um acréscimo e é, muitas vezes, influenciada pelas línguas que o aluno já possui. Esse termo possui uma denotação mais abrangente para se referir à aprendizagem de uma nova língua:

O uso do termo "adicional" traz vantagens porque não há necessidade de se discriminar o contexto geográfico (língua do país vizinho, língua franca ou internacional) ou mesmo as características individuais do aluno (segunda ou terceira língua). Nem mesmo os objetivos para os quais o aluno estuda a língua precisam ser considerados nessa instância. (LEFFA; IRALA, 2014, p. 32)

Além disso "língua adicional" também corresponde a compreensão e respeito pela multiplicidade de línguas e culturas no contexto de globalização em que vivemos.

Posto isso, é relevante pensarmos em como ocorre essa aprendizagem de novas palavras em línguas adicionais. Desta forma, nas seções seguintes faremos um levantamento de algumas estratégias utilizadas, levando em conta que não existe estratégia melhor ou pior, certa ou errada. Todas são válidas e podem ser empregas de modo a contribuir para o enriquecimento lexical.

Nesse mesmo sentido e levando em conta que na sociedade atual o texto não verbal tem bastante espaço, uma vez que informa de maneira mais rápida atendendo ao imediatismo das pessoas, pensamos nas vantagens dos recursos visuais para aprendizagem de léxico de línguas adicionais. E, além disso, buscamos trabalhar com esses recursos visuais aliados à tecnologia de RA, apresentando um aplicativo de celular que tem a função de traduzir as palavras desconhecidas por meio de imagens em 3D (três dimensões).

\section{Estratégias de Ensino e de Aprendizagem}

Listas de palavras, escuta e repetição, associações, traduções, reescrita, uso da língua em situações comunicativas reais em sala de aula, uso do dicionário, comparações, etc. Essas são algumas das muitas estratégias utilizadas para a aprendizagem de vocabulário em línguas adicionais. 
Como podemos ver a aprendizagem de palavras não possui uma maneira específica de ocorrer. Tal como defende Leffa (2016), o ensino e aprendizagem de vocabulário já foram vistos, ao longo dos anos, como componente essencial da língua, assim como componente acessório. Sua ênfase ora estava nos aspectos externos, ou seja, no material apresentado ao aluno e ora estava nos aspectos internos, que diz respeito ao que o aluno faz para aprender novas palavras da língua estudada.

Com essas colocações, é importante destacar que hoje todos esses elementos são importantes, tanto o material, como a ação do aluno em busca do conhecimento de palavras novas. Diante disso, cabe ao professor apresentar a ele várias possibilidades de aprendizagem.

Las posibilidades de enriquecimiento del vocabulario son muy amplias pero la actividad que realiza el alumno no debe limitarse a reunir palabras, sino a señalar las variedades significativas de cada una de ellas, a usarlas en diferentes niveles o registros. Asimismo, el léxico que va aprendiendo el alumno ha de actualizarse periódicamente en los textos o actividades posteriores (MOLINA, 1997, p. 76). ${ }^{1}$

Paiva (2004) se fundamenta em Harmer (1991) para explicar que as atividades para aprendizagem de palavras podem ser divididas em três seções: apresentação, técnicas de descoberta e prática. Ao primeiro grupo estão as estratégias com listas de palavras da mesma categoria, o uso de objetos, gravuras, mimica, gestos, explicação, tradução, descrições, sinônimos etc. Já ao segundo grupo pertencem as combinações de palavras com gravuras, mapas semânticos, uso do contexto, uso de prefixos/sufixos e os textos orais e escritos com vocabulário especifico. Por fim, o terceiro grupo, chamado de prática, engloba atividades como gestos, uso de vocábulos normalmente confundidos, atividades para colocar as palavras em ordem etc.

A primeira estratégia, normalmente a mais usada, são as listas de vocabulário. Essas podem ser organizadas a partir de traduções, sinônimos, antônimos e definições, tal como defende Paiva (2004). Da mesma forma, a autora também nos apresenta os mapas conceituais como sendo relevantes para a organização de novas palavras, sendo que esses podem ser construídos pelo próprio aluno da forma que ele melhor compreenda.

Segundo Paiva (2004), outras estratégias são as gradações de sentidos e o estudo da composição das palavras a partir dos prefixos e sufixos. Essas atividades ajudam a conhecer novas palavras e fazer associações com outras que são derivadas dessa primeira palavra aprendida, um exercício muito válido, que os professores devem fazer com os seus alunos. 
Além disso, Paiva (2004) também cita as tecnologias como sendo importantes nesse processo, uma vez que os alunos fazem uso constante delas fora da sala de aula. Sendo assim, a autora cita jogos digitais de palavras cruzadas, anagramas, caça palavras, jogos da memória, forca, entre outros.

Por fim, cabe ainda destacar a estratégia que envolve a associação de imagens, a qual procuramos dar ênfase neste trabalho. Segundo Paiva (2004, p. 18) "As gravuras são importantes auxiliares para a aprendizagem de vocabulário. $\mathrm{O}$ recurso visual constitui uma boa estratégia de memória, pois associa um conceito a uma forma icônica."

A partir disso, daremos continuidade às discussões de como os recursos visuais são importantes no processo de ensino e de aprendizagem e, mais especificamente, da aprendizagem de novas palavras em línguas adicionais.

\section{Importância dos Recursos Visuais}

Como já mencionamos, um recurso muito relevante para a aprendizagem de novas palavras em línguas adicionais é o visual. Este recurso está muito presente na sociedade moderna de maneira geral, uma vez que tem a capacidade de comunicar de forma mais rápida e simplificada que o texto escrito, isso porque se vale de imagens, fotografias, desenhos, vídeos, animações, etc. Além disso, os recursos visuais representam uma quebra na hegemonia da tradição em que a escrita era considerada uma das únicas formas de transmissão de informação (PROCÓPIO, 2007).

Os alunos, assim como a sociedade em geral, estão vivendo em um período do imediatismo, onde o não verbal é priorizado, tal como apresentam Costa e Costa (2010, p. 194) "É a imagem criando, reproduzindo, comunicando valores, crenças e ideologias.”. Isso mostra que as atividades que o aluno pratica fora da sala de aula estão muito mais ligadas aos recursos visuais, como por exemplo nas redes sociais, jogos, vídeos, stickers de whatsapp etc.

Desta forma, o professor pode se utilizar dos recursos visuais aliados às tecnologias, componentes que já fazem parte da vida dos estudantes:

[...] utilizar os recursos visuais nos espaços escolares possibilita maior interatividade com diferentes conhecimentos diferenciados, navegando no mundo do saber, por intermédio de um conjunto de palavras, ideias e imagens representativas e interligadas à tecnologia, buscando significado existente, além do mais, produzindo outros, sistematizando, dessa maneira, a aprendizagem. (SOUZA, 1997, s. p) 
No entanto, para que isso aconteça, o professor precisa entender e deixar claro ao seu aluno que os recursos visuais também são textos, possuem propriedades interpretativas e estão carregados de sentindo. Nesse âmbito, podemos mencionar o letramento visual, o qual corresponde a um conjunto de habilidades aprendidas para a identificação, compreensão, interpretação e produção de qualquer informação visual de forma consciente e crítica, assim como defende Procópio (2007).

Oliveira (2006) recorre a Pennings para explicar que as matérias que embasam o letramento visual buscam estudar os processos físicos envolvidos na percepção visual, o uso das tecnologias para a representação da imagem visual, assim como, o desenvolvimento de estratégias para interpretar o que é visto.

Quanto a essas questões de interpretação, como apresentam Costa e Costa (2010) é necessário levar em conta o tipo de recurso visual que será utilizado, pois ele pode gerar más interpretações, "[...]esses recursos podem, às vezes, distrair, confundir, atrapalhar e obscurecer o significado do texto." (COSTA E COSTA; 2010, p. 195).

Reforçando o posicionamento anterior, Souza (1997) afirma que assim como ocorre na interpretação verbal, a interpretação da imagem também pressupõe uma relação com a cultura, com o social, com o histórico e com a formação social dos sujeitos. Dessa maneira, torna-se importante analisar muito bem as imagens propostas aos alunos, de modo a alcançar o objetivo que se tem com aquela atividade sem que se torne um exercício confuso.

Já quando tratamos dos recursos visuais no ensino e na aprendizagem de novas palavras, Procópio (2007) ressalta sobre a sua importância, uma vez que promove uma maior retenção de palavras novas. A partir do trabalho de Rodrígues e Sadoski (2000) e Jolly (2003) a autora enfatiza que a multimodalidade, visual mais verbal, promove uma dupla codificação e consequentemente uma compreensão mais profunda e melhor lembrança da palavra aprendida.

Além disso, Procópio (2007) também recorre a Mayer (1994, 1998, 2001) para explicar os processos mentais que ocorrem quando estamos diante de uma palavra desconhecida em língua adicional apresentada por meio de recursos verbais e visuais. Segundo ele, ocorrem conexões mentais entre as representações pictóricas e verbais, sendo que a seleção e organização mental das informações para cada um dos recursos ocorre de forma separada.

Outro ponto importante também ressaltado por Procópio (2007) é que não são todas as palavras que podem ser utilizadas para a aprendizagem de vocabulário. 
Os substantivos concretos normalmente são mais fáceis de serem visualizados, já os abstratos dificilmente conseguimos associá-los a uma imagem.

Partindo disso, nosso interesse é também propor uma estratégia para aprendizagem de vocabulário com o uso de recursos visuais. Nesse trabalho, apresentaremos um aplicativo que criamos para tradução de palavras da língua espanhola por meio de imagens em RA, ou seja, imagens em 3D (3dimensões). Na próxima seção, serão explicitados o funcionamento e os benefícios dessa estratégia.

\section{Aprendizagem de novas palavras em Línguas Adicionas por meio de RA}

Antes de tratar sobre a RA para o enriquecimento de vocabulário em línguas adicionais, é necessário levar em conta que a literatura sobre essa temática vem se difundindo bastante, mas ainda é bastante limitada na área da educação. Com isso, torna-se importante pensar sobre tal tecnologia aliada ao ambiente escolar:

Su importancia en la educación deriva de las posibilidades que nos ofrece esta tecnología para enriquecer la información que se presenta, proporcionando una combinación de información digital e información física en tiempo real por medio de distintos soportes tecnológicos como por ejemplo las Tablets o los smartphones, para crear con ello una realidad nueva. (OZUNA E PÉREZ, 2016, p. 25) ${ }^{2}$

Sendo assim, a RA consiste em uma ferramenta tecnológica que acrescenta informações virtuais a um espaço físico, em tempo real, através de um celular ou tablet. Para compreender melhor, tomemos por exemplo a Figura 1, na qual há um marcador, que normalmente é um QR Code apresentado no material impresso. A partir desse marcador o usuário aponta a câmera do seu celular e aparece uma imagem em 3D.

Figura 1: QR Code e objeto em RA
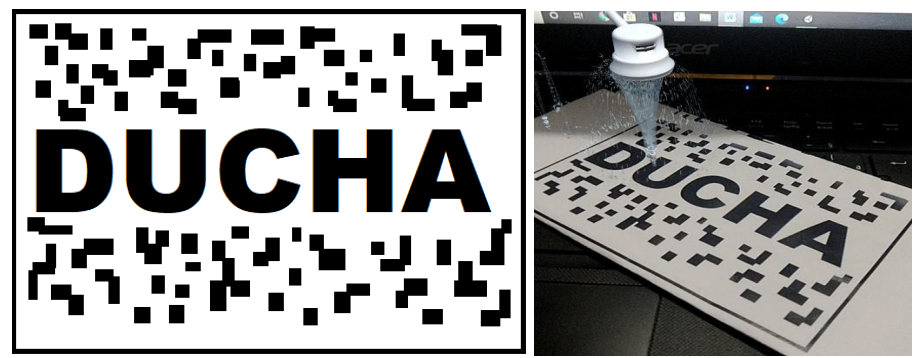
Vale complementar que a RA trata de uma interação em tempo real, ou seja, quando o usuário movimentar o marcador, a imagem em 3D também se moverá na tela do dispositivo:

Além de permitir que objetos virtuais possam ser introduzidos em ambientes reais, a RA proporciona também, ao usuário, o manuseio desses objetos com as próprias mãos, possibilitando uma interação atrativa e motivadora com o ambiente. (PREZOTTO; SILVA; VANZIN, 2013, p. 232)

Esses dois aspectos, motivação e interação, são os melhores caracterizadores da RA:

Dentre várias vantagens da RA encontram-se: a motivação do estudante, a interação em as disposições multimídia podendo ver de forma tridimensional figuras, remete o aluno sair do âmbito da sala de aula e oferece a capacidade de se colocar dentro do mundo virtual, a criatividade, o desenvolvimento cultural, a habilidade e o domínio nas técnicas computacionais. (OLIVEIRA et al, 2016, p. 733):

Partindo dos conceitos mencionados acima quanto à importância das imagens no processo de ensino e de aprendizagem e também levando em conta a relevância da RA, procuramos desenvolver um aplicativo que aliasse essas duas potencialidades com o intuito de traduzir palavras da língua espanhola por meio de imagens em 3D. O aplicativo piloto foi chamado de ERA, que significa, Espanhol Realidade Aumentada (Figura 2).

Figura 2: Aplicativo Piloto: ERA

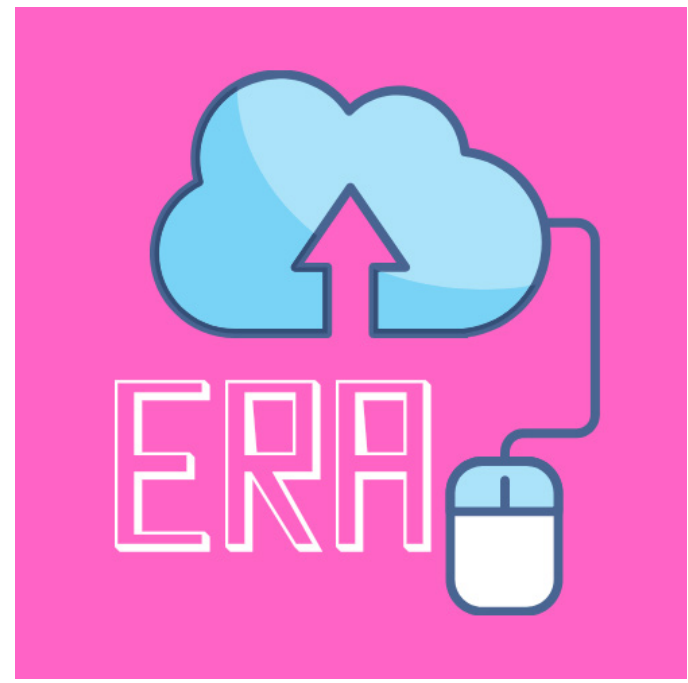


Este aplicativo funciona da seguinte forma: Prevendo algumas dificuldades léxicas por parte dos alunos, ao organizar seu material de ensino, o professor de língua espanhola já disponibiliza um QR Code para determinadas palavras. O aluno, assim, tendo dificuldade lexical com estes itens selecionados pelo professor, digitalizará com sua câmera de celular, a partir de nosso aplicativo, o código em destaque. Com isso, aparecerá uma imagem em 3D com a representação daquela palavra. (Figura 3).

Figura 3: Funcionamento do APP. Era: Marcador + Objeto RA
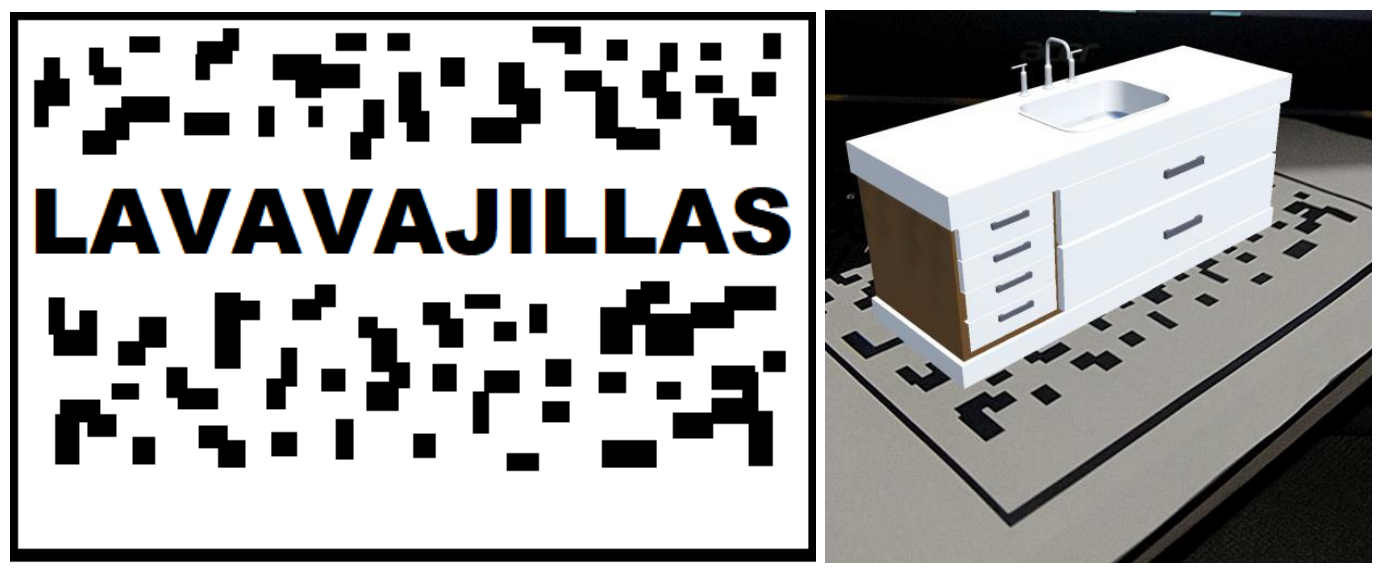

Vale ressaltar que não são todas as palavras do texto que serão traduzidas de tal forma, mas, sim, as mais relevantes serão dotadas de RA. Além disso, o aluno estará acessando a informação de uma forma diferente, não irá buscar no dicionário ou receber a tradução do professor, ele terá que se mobilizar para saber o significado da palavra em questão, despertando a autonomia quanto a sua aprendizagem.

O aplicativo ERA foi desenvolvido a partir da plataforma Unity e pode ser alimentado por novos elementos a qualquer momento. No entanto, a ferramenta está em fase final de teste, por isso, ainda não está disponível para acesso público.

Desta forma, a partir do aplicativo de RA para a tradução e enriquecimento de vocabulário em língua adicional, e também a partir deste trabalho, pretende-se dar ênfase aos recursos visuais e às tecnologias, pois são ferramentas muito válidas nas mais diversas áreas. 


\section{Considerações Finais}

A partir deste trabalho, podemos observar que para aprender novas palavras em línguas adicionais, existem várias estratégias. Essas estratégias derivam da grande gama de recursos existentes hoje (verbais e não-verbais/ impressos e digitais) que podem ser usados de diferentes formas e em diferentes momentos da caminhada do estudante. Sendo assim, ele pode aprender a partir de uma estratégia, bem como utilizar-se de várias.

A estratégia que leva em conta a utilização de recursos visuais tem contribuído bastante para a área do ensino de línguas, uma vez que, segundo Procópio (2007), promove um duplo armazenamento, tanto linguístico como visual, ativando dois sistemas mentais.

Aliada a essas estratégias estão as tecnologias com sua infinidade de recursos disponíveis gratuitamente para serem utilizados, dependendo somente da criatividade, do interesse e da disposição em aprender a usá-las por parte do professor ou usuário. Nessa perspectiva, está a tecnologia de RA associada à aprendizagem de novas palavras em língua espanhola.

Pensando em uma ferramenta de tradução de palavras, desenvolvemos um aplicativo em RA, visando todas os benefícios que esse tipo de ferramenta pode oferecer. Entre os principais, estão a interação, motivação e a autonomia, pois exige a mobilidade do aluno para aprender o que significa determinada palavra o que torna o processo mais significativo.

Por fim, é importante ressaltar que cabe ao professor utilizar distintas estratégias para o ensino de vocabulário, uma vez que estará oportunizando aos alunos essa diversidade de formas de aprender. 


\section{ERA app: a strategy for learning vocabulary of spanish as additional language using Augmented Reality}

\section{Abstract}

This work aims to present and reflect on some strategies used for learning additional language vocabulary, especially with regard to activities involving visual resources and the use of Augmented Reality (AR) technology. Therefore, we seek to investigate the most relevant and usual strategies and how visual resources and AR technologies can contribute to such a process. In addition, we will present an AR application that we developed for translation of words in Spanish. This application was named ERA, Spanish Augmented Reality.

Keywords: Spanish, strategies, learning, vocabulary, Augmented Reality.

\section{Notas}

1 As possibilidades de enriquecimento de vocabulário são muito amplas, mas a atividade realizada pelo aluno não deve limitar-se a reunir palavras, deve corresponder as variedades significativas de cada uma delas, as utilizando em diferentes níveis ou registros. Da mesma forma, o léxico que o aluno aprende precisa ser atualizado periodicamente a partir dos textos e atividades posteriores. (MOLINA,1997, p. 76).

2 Sua importância na educação deriva das possibilidades que nos oferece esta tecnologia para enriquecer a informação apresentada, proporcionando uma combinação da informação digital e informação física em tempo real por meio de distintos suportes tecnológicos como por exemplos os Tablets e os Smartphones, para criar com isso uma realidade nova (OZUNA E PÉREZ, 2016, p. 25)

\section{Referências}

Costa, C. J. F. S. Costa, M. A. M. (2010) O papel das imagens no ensino de leitura em língua inglesa: uma perspectiva discursiva. Revista Lumen Et Virtus. v. 1, n. 2.

Leffa, V. J. (1997) Língua Estrangeira: ensino e aprendizagem. Pelotas: Educat, 2016. MOLINA, C. R. G. El léxico y su didáctica: uma propuesta metodológica. REALE. 7, p. 69-91.

Leffa, Vilson J.; IRALA, Valesca. (2014). O ensino de outra(s) língua(s) na contemporaneidade: questões conceituais e metodológicas. Educat. Pelotas, 2014, p. 21-48.

Oliveira, R.C.; Silva, D.; Fernandes, F. G.; Oliveira, L. C.; Oliveira, E. C. (2016) Aplicativo de Aprendizagem Móvel utilizando Realidade Aumentada para Ensino de Língua Inglesa. Anais dos Workshops do V Congresso Brasileiro de Informática na Educação (CBIE 2016), p. 731-740.

Osuna, J. M. B. Pérez, O. M. G. (2016) Produción de recursos de aprendizage apoyados em Realidad Aumentada por parte de estudiantes de magistério. Revista de Educación, Mediatica y TIC. p. 23-38.

Paiva, V. L. M. O. (2004) Ensino de vocabulário. In: DUTRA, D. P \& MELLO, H. A gramática e o vocabulário no ensino de inglês: novas perspectivas. Belo Horizonte: Faculdade de Letras/ UFMG. 
Prezotto, D.E; Silva, T. L; Vanzin, R. (2013) Realidade Amentada Aplicada a educação. Anais do EATI - Encontro Anual de Tecnologia da Informação e Semana Acadêmica de Tecnologia da Informação. Frederico Westphalen n.1, p. 322-326.

Procópio, R. B. (2007) Os recursos visuais no ensino-aprendizagem de vocabulário de língua estrangeira. Dissertação (Programa de pós-graduação em Linguística ) Área de Linguística e Ensino de Língua, Universidade Federal de Juiz de For a.

Souza, T. C. C. (1997) Discurso e Imagem Perspectivas de análise não verbal. $2^{\circ}$ Colóquio Latinoamericano de Analistas Del Discurso, La Plata e Buenos Aires. 